\title{
A COR DA DIFERENÇA NA CONSTRUÇÃO DA IMAGEM DO NEGRO NA POEMA “SOU NEGRO” DE CUTI
}

\section{EL COLOR DE LA DIFERENCIA EN LA CONSTRUCCIÓN DE LA IMAGEN NEGRA EN EL POEMA CUTI "YO SOY NEGRO"}

\author{
Eliana Almeida Marques ${ }^{1}$ \\ Nilmara Milena da Silva Gomes²
}

RESUMO: O presente trabalho - fruto final de artigo final da especialização em Língua Portuguesa e Literatura - pretende depreender no enunciado da poesia a semântica que configura a imagem do negro construída a partir da representação de um sujeito lírico que se declara negro, por meio de elementos, tématicas que representam e fortalecem a imagem de um ethos que configura um sujeito afrodescendente construída na poema "Sou negro" de Cuti, a partir da concepção (Maingueneau, 1997) sobre a construção da imagem de si no discurso. O trabalho propõe compreender as representações discursivas que podem se manifestar nas práticas do sujeito lírico na enunciação que levam a uma configuração da imagem do negro no discurso da literatura negra. Para isso, os alicerces teóricos foram Maingueneau (1997), que vereda pela noção do ethos no âmbito da Análise do Discurso, Bernd (1988) e Proença Filho (2004), incumbido pela Literatura Negra. E para análise do estudo foi utilizado a poesia "Sou negro", autoria de Cuti. Além disso, verificou-se que é possivel compreender pelo eu-lirico a presença de um éthos que se assume negro na poesia examinada.

Palavras-chave: Sujeito Negro, Enunciação, Ethos.
RESUMEN: El presente trabajo, el resultado final de un artículo presentado y aprobado en el Curso de Postgrado Lato Sensu, especialización en Lengua y Literatura portuguesas, tiene como objetivo comprender la imagen del enunciador de poesía negra, "Sou Negro" por el autor Cuti, desde la concepción (Maingueneau, 1997) sobre la construcción de la autoimagen en el discurso. En un intento por comprender las representaciones discursivas que pueden manifestarse en las prácticas del yo lírico en la enunciación que conducen a una configuración de la imagen del negro en el discurso de la literatura negra. Para esto, los fundamentos teóricos fueron Maingueneau (1997), que sigue la noción de ethos en el contexto de Discourse Analysis, Bernd (1988) y Proença Filho (2004), confiada por la Literatura Negra. Y para el análisis del estudio se utilizó la poesía "Sou negro", escrita por Cuti. Además, se ha descubierto que el letrista puede comprender la presencia de un ethos que asume la negrura en la poesía examinada.

Palabras claves: Ethos, Enunciación, Sujeto Negro.

1 Pós-graduanda em Língua Portuguesa e Literatura da Universidade Estadual de Roraima.

2 Professor(a) na Especialização em Ensino de Língua e Literatura da Universidade Estadual de Roraima. 


\section{INTRODUÇÃO}

São muitas as vertentes que tem o discurso como mote de análise, contudo, para esta pesquisa, nos deteremos aos elementos que constroem a enunciação. Desta maneira, este artigo, propõe-se a analisar a construção da imagem do negro anunciada pelo eu lírico na poesia "Sou negro" de Cuti.

Nesse direcionamento, vislumbramos compreender as camadas da discursividade, ideologias construídas no texto, através da figura produzida pelo eu lírico no ato comunicativo do discurso, na busca de compreender os elementos que marcam e representam o indivíduo e comunidade pertencente a população afrodescendente. E quais signos que deixam lacunas no corpo enunciativo que permitem o leitor a associarem a pessoas com esse biotipo, pretende-se assim, depreender no enunciado da poesia a semântica que configura a imagem do negro construída a partir da representação de um sujeito lírico que se declara negro, por meio de elementos, temáticas que representam e fortalecem a imagem de um ethos que configura um sujeito afrodescendente construída na poesia "Sou negro" de Cuti.

Para esse intento, o método utilizado para a pesquisa foi o bibliográfico, utilizada no sentido de compreender a imagem do negro, através do ethos do enunciador do sujeito negro incorporado na poesia de Cuti (2011). Desse modo, pretendemos, também, compreender como os estereótipos são combatidos pelas formações discursivas poéticas, a respeito dessa construção de imagem representada do sujeito negro.

Diante desse contexto, para atingir o objetivo, esta pesquisa está dividida em três sessões, a primeira apresenta uma reflexão sobre a palavra ethos na perspectiva da análise do discurso, com um breve relato sobre a história de seu surgimento, bem como o autor precursor e outros que se filiam. A segunda, concepções e sentidos sobre a presença do negro na literatura brasileira, com conceito sobre a literatura negra e autores que representam esse ramo. E a terceira com a análise da imagem de um ethos que configura a imagem de um sujeito negro, com ênfase na poesia "Sou negro" de Luiz Silva, pseudônimo Cuti.

Assim, torna-se pertinente a conexão entre a noção de ethos cunhada por Maingueneau (1997) que permeia o processo do ato de dizer, na qual possibilita a compreensão do processo semântico que tematiza as questões dos afrodescendentes no poema "Sou negro". Por essas razões, o presente trabalho se estrutura no âmbito da Análise do Discurso, para constatar o estilo do enunciador. E para descobrir a imagem negra representada desse sujeito no texto, utilizou-se os teóricos Freyre (2011) e Bernd (1988) que estudam sobre o campo da literatura negra no Brasil.

\section{A PALAVRA ETHOS NA PERSPECTIVA DAANÁLISE DO DISCURSO}

O Ethos foi originalmente compreendido pela Retórica como característica da maneira de dizer implícita dos oradores, ou seja, a forma como se expressam para encantar o ouvinte construindo uma representação de imagem favorável de si. Isso não quer dizer que os oradores falam sobre si mesmos, mas revelam algo na forma de se expressarem. Assim, o êxito destes ethe surgiu pela maneira que eles atravessam pela enunciação, sem determinar sua função (MAINGUENEAU 1997).

A palavra Ethos tem o seu conceito estudado por Maingueneau desde a década de 1980. Dedicou-se ao aperfeiçoamento do conceito de Ethos, de modo que as premissas que o norteavam passassem a ser estudadas a partir da esfera da Análise do Discurso. 
Diante disso, Maingueneau (2008) retoma a fórmula de Gilbert, mencionada por Aristóteles que trata de um triângulo da retórica que refere aos argumentos, os quais se dividem em três fundamentos: o primeiro nomeado por logos que se refere aos argumentos objetivos e racionais; o segundo chamado por pathos, referentes as paixões e convencimento do enunciatário; e o terceiro denominado por ethos, que se vincula as condutas éticas e morais produzidos pelo enunciador em seu discurso. Na teoria do ethos, alude sobre “[...] o caráter moral que o discurso deve, eu diria, quase todo seu poder de persuasão" (AMOSSY, 2005, p. 10). A partir dessa descrição, compreendemos as razão que levaram Maingueneau ao estudo do Ethos pelo viés da Análise do Discurso por (AMOSSY 2008, p. 70)

seu laço crucial com a reflexividade
enunciativa e a relação entre corpo e discurso
que ela implica. É insuficiente ver a instância
subjetiva que se manifesta por meio do
discurso apenas como estatuto ou papel. Ela
se manifesta também como uma 'voz' e, além
disso, como 'corpo enunciante',
historicamente especificado e inscrito em
uma situação, que sua enunciação ao mesmo
tempo pressupõe e valida progressivamente.

Assim, Maingueneau (2005b) declara que todo texto escrito ou oral contém uma vocalidade subjetiva que o enunciador produz no enunciado, através de um tom de vestígios oferecido por quem fala, determinando um corpo do enunciador. Assim, "O que é dito e o tom com que é dito são igualmente importantes e inseparáveis (MAINGUENEAU, 1997, p. 46). Esses vestígios, ao serem aferidas na dimensão semântica do discurso, mostram o estilo de uma pessoa personificada, formando a imagem do enunciador. Nesse sentido, essas marcas no texto permitem ao leitor subtrair o ethos mostrado, por meio das especificidades de apontamentos do próprio corpo no discurso.

Dessa maneira, por intermédio da leitura, o leitor formula a imagem do fiador pelos sinais apresentados no texto, já que "a leitura faz emergir uma origem enunciativa, em uma instância subjetiva e encarnada que exerce o papel de fiador" (MAINGUENEAU, 2005b, p. 72). Esse fiador se reveste de um caráter e uma corporalidade, isso não que dizer que se trata do autor em si propriamente dito, mas do corpo do enunciador que é manifestado em "um conjunto difuso de representações sociais valorizadas ou desvalorizadas, de estereótipos sobre os quais a enunciação se apoia e, por sua vez, contribui para reforçar ou transformar." (MAINGUENEAU, 2005b, p. 72).

Diante disso, a compreensão do discurso designa a maneira que o leitor se apropria do ethos no processo de incorporação. Esse incorporar se liga à enunciação e não ao conhecimento exterior vivenciado pelo enunciador. Pois, quando os elementos do ethos integram a discursividade, o discurso fica indissociável da maneira que "toma corpo". Diante do exposto, Maingueneau (2005a) fala sobre a noção de incorporação que designa a formação discursiva e o ethos que se manifesta no procedimento enunciativo e que atua em três registros intimamente articulados. Maingueneau (2005a, p. 99) explica esse processo:

\footnotetext{
a enunciação leva o co-enunciador a conferir um ethos ao seu fiador, ela lhe dá corpo;

o co-enunciador incorpora, assimila, desse modo, um conjunto de esquemas que definem para um dado sujeito, pela maneira de controlar seu corpo, de habitá-lo, uma forma específica de se inscrever no mundo;

essas duas primeiras incorporações permitem a constituição de um corpo, o da comunidade imaginária dos que comungam na adesão a um mesmo discurso.
}

Nesse sentido, a incorporação permeia diretamente sobre a eficácia do discurso, na questão de atribuição de um posicionamento sobre o que foi explícito. Assim, essa eficácia do ethos surge na enunciação sem ser dito no enunciado, mas na "[...] aparência que lhe confere a fluência, a entonação, calorosa ou severa, a escolha das palavras, 
dos argumentos [...]" (DUCROT apud MAINGUENEAU, 2005, p. 71), visto que o ethos não é dito, mas sim mostrado.

Desvendados alguns aspectos sobre ethos, iremos discorrer, de maneira mais específica sobre como o eu-lírico da poesia "Sou negro” de Cuti (2011) denominada de literatura negra, cria o estilo próprio do enunciador do sujeito negro, pois o discurso à luz de Maingueneau (2005) qualifica pela sua natureza particular como um discurso constituinte, ou seja, ao se tornar particular os elementos que formam o discurso de um sujeito, mostra-se um estilo próprio de representação no enunciado.

\section{CONCEPÇÕES E SENTIDOS SOBRE A PRESENÇA DO NEGRO NA LITERATURA BRASILEIRA}

Desde o século XVI, Freyre (2011) afirma que o negro participou na formação da população do Brasil de maneira ativa, embora na posição de escravos, mas foram co-colonizadores, igualmente aos europeus. Desse modo, não tem como não destacar a importância dessa herança cultural étnica na formação da sociedade brasileira, pois foram fundadores de uma nova cultura.

Posto isto, observa-se que na história da literatura brasileira canônica a figura do negro nas narrativas, não passa de um tratamento marginalizador. Essa noção de raça, Hall (2015) assevera que é formada pelo construto sociodiscursivo, ou seja, a visão do negro foi formada pelo outro. Historicamente, a sociedade produziu um sentido depreciativo desse sujeito. Todavia, evidenciaram-se, dois posicionamentos no percurso literário: no primeiro, o negro está na condição de objeto do discurso, ou seja, a literatura fala sobre o negro, com o olhar distanciado da realidade. Bosi (2002), argumenta que ser objeto na literatura é ser tema, personagem, ou compreender o enunciador desse sujeito como processo simbólico.
Assim, o afrodescendente nas narrativas literárias eram personagens, temas de assunto pertencentes da formação histórica cultural do Brasil. Na qual encadeou, "procedimentos que, com poucas exceções, indiciam ideologias, atitudes e estereótipos da estética branca dominante" (PROENÇA FILHO, 2004, p.161).

Como já foi dito, o negro sempre participou do Sistema Literário brasileiro, porém na maioria das vezes sua voz foi silenciada, já que a descrição proferida era fundamentada na visão do colonizador, ou seja, o outro era o porta-voz. Dessa maneira, divulgou-se uma imagem racista, depreciativa, xenófoba e com aversão religiosa. Destarte, a classe branca que dominava os bens culturais, o negro ficou em um posicionamento a margem da sociedade. Dessa maneira, predominam os estereótipos:

\begin{abstract}
O personagem negro ou mestiço de negros caracterizado como tal ganha presença ora como elemento perturbador do equilíbrio familiar ou social, ora como negro heroico, ora como negro humanizado, amante, força de trabalho produtivo, vítima sofrida de sua ascendência, elemento tranquilamente integrador da gente brasileira, em termos de manifestações. (PROENÇA FILHO, 2004, p.174)
\end{abstract}

No exemplo acima, configura-se uma imagem estereotipada do negro, vítima quando era escravo, tratado como objeto ideológico, na pretensão de exaltar a liberdade e defesa do absolutismo. Esses acontecimentos vivenciados por eles eram retratados sob a perspectiva do colonizador. Todas as situações postas, mostraram uma literatura sobre o negro

Por sua voz, no segundo posicionamento esse negro se torna sujeito do seu discurso e assume a voz do discurso, numa visão compromissada com a imagem, empenhado em legitimar a sua identidade dentre outros anseios sociais, numa perspectiva engajada. Pois, para Denis (2002, p. 25), a literatura engajada não é a que abdica da atividade sobre o trabalho da forma, "sem a qual ele [o 
autor] faria literatura de propaganda; é antes uma questão de [...] modificar-lhe o sentido, deixando de fazer disso um fim em si para tentar fazê-la servir [às causas sociais]". Também nesse sentido,

os escritores consideram-se engajados e
definem este engajamento: a) pelo
"compromisso em expressar a verdadeira
realidade de seu povo"; b) pela contribuição
que a literatura trará "ao progresso dos povos
negros"; c) pelo compremetimento e,
consequente, de uma cultura "positiva e
fecunda"; (BERND, 1988, p. 28).

Baseado nestes postulados, o autor Cuti (2005) na perspectiva engajada tenta combater as controvérsias políticas impostas, agindo conscientemente, ao se reconhecer com parte do mundo em que está inserido. Esse reconhecimento, entende-se como identidade que pode ser considerada uma qualificação do sujeito no discurso (JACQUES, 1998). Também pode ser envolvido em uma manifestação de consciência, na qual leva a uma intencionalidade de anseios de mudança da ideologia imposta. É nesse sentido, de tentativa de desvincular os estereótipos sociais que Cuti (2005) expressa em seus escritos.

\section{A IMAGEM DE UM ETHOS QUE CONFIGURA O SUJEITO NEGRO NA POESIA “SOU NEGRO” DE CUTI}

Todo problema para ser pesquisado, requer estudos, consultas de bibliografias que abordem o tema, ou seja, pesquisas em livros, artigos, documentos, entre outros. Nessa perspectiva, o método de pesquisa bibliográfica "busca conhecer e analisar as contribuições culturais ou científicas do passado existente sobre um determinado, tema ou problema." (CERVO,1983, p.55). Isso quer dizer que o pesquisador utiliza dados devidamente registrados para basear o estudo (SEVERINO, 2007, p.122).

Assim, o corpus desse estudo é construído pela análise de alguns versos que propõe depreender a imagem do negro, atráves do ethos do enunciador negro do poema de Cuti (2011) "Sou negro", publicado em Antologia de poesia afrobrasileira. Na qual pretente compreender o estilo próprio dado na enunciação que contrói uma imagem do enunciador que representa o sujeito negro. Nesse contexto, o estilo será estudado pelo conceito de Maingueneau sobre o ethos, na tentativa de buscar elementos que possibilitam a identificação do ethos do eu-lírico como sujeito negro nos versos do poema, por intermédio da linguagem poética.

Cuti, pseudônimo de Luiz Silva, nasceu em Ourinhos, no interior de São Paulo, em 31 de outubro de 1951. Formou-se em Letras com habilitação em Português/Francês na Universidade de São Paulo, em 1980. É mestre em Teoria da Literatura e Doutor em Literatura Brasileira pelo Instituto de Estudos da Linguagem - Unicamp (1999/2005). Ele é um dos militantes mais engajados da literatura afro-brasileira. Criador, fundador e membro do Quilombohoje-Literatura, de 1983 a 1994, manteve uma série Cadernos Negros, de 1978 a 1993.

Cuti, guiado pela palavra resistência, criou uma produção diferenciada, com um estilo específico, inspirado nos elementos culturais de sua origem, com objetivo de resgatar a sua dignidade e a do seu povo. Feitas essas observações, esse estudo baseiase na Análise do Discurso cunhada por Maingueneau (1997) sob a ótica da constituição do ethos como marca de estilo do enunciador do sujeito negro. Na tentativa de encontrar como o eu-lírico desse enunciador constrói caminhos para persuasão na produção de sentidos no texto, pautado em sua origem étnica, principalmente, no modo de dizer desse sujeito, optamos por analisar apenas alguns versos devido a extensão do artigo.

Isto posto, chamamos a atenção para a 
afirmativa de que é no texto que podemos depreender, reconstruir e averiguar cada especificidade produzida no discurso, através da maneira de dizer do sujeito na enunciação, é no discurso produzido que demonstra sua formação de mundo. Nessa tomada de conscienência que a literatura negra reafirma seu discurso, numa "tentativa de preencher vazios criados pela perda gradativa de identidade" (BERND, 1988, p. 22). Assim, utiliza-se de elementos significativos que instituem a ressignificação de identidade, individualiza uma imagem de sujeito, desenhando um esboço de enunciador negro no texto. À luz de tais conceitos, busca-se encontrar nos versos do poema as marcas do éthos que identificam a imagem do enunciador que representa um sujeito negro.

O éthos e o estilo são delineados nos elementos discursivos textuais deduzidos por meio de indicações deixadas pela enunciação anunciada, na qual propõe um referencial de mecanismo para construção de sentidos, define um modo de dizer, determinando o estilo próprio de Cuti, esboçado na poesia que encena ao enunciatário a imagem do enunciador, denominada éthos. À luz de tais conceitos, busca-se encontrar na poesia as marcas do ethos que identificam o enunciador do sujeito negro. Baseado nos conceitos expostos anteriormente, far-se-á a análise da poesia transcrita a seguir:

Sou negro
Sou negro
Negro sou sem mas ou reticências
Negro e pronto!
Negro pronto contra o preconceito branco
O relacionamento manco
Negro no ódio com que retranco
Negro no meu riso branco
Negro no meu pranto
Negro e pronto!

Beiço
Pixaim
Abas largas meu nariz
Tudo isso sim
- Negro e pronto! -
Batuca em mim
Meu rosto
Belo novo contra o velho belo imposto
E não me prego em ser preto
Negro pronto
Contra tudo o que costuma me pintar de sujo
Ou que tenta me pintar de branco
Sim
Negro dentro e fora
Ritmo - sangue sem regra feita
Grito - negro - força
Contra grades contra forças
Negro pronto
Negro e pronto
(CUTI, 2011, p. 145)

A abertura do poema se manifesta da seguinte forma "Sou negro", a imagem construída possibilita sentido ao eu-lírico, tanto que ele se inclui no discurso poético, ao usar a expressão "sou", verbo em primeira pessoa do discurso, também marca um eu oculto no verso. Para Bernd ( 1988, p.12), "discurso em primeira pessoa (...), na constituição do sujeito do discurso poético, cuja palavração desvela a sua negritude.” Dessa maneira, o enunciador intitula-se pertencente ao enunciado, assim o ethos da poesia corresponde ao sujeito lírico. Percebese que o ethos representa uma identidade. Com isso, pode-se dizer que o enunciador se declara negro no discurso poético.

Então, o eu lírico ao se identificar determina uma imagem que reflete um sentido de individualidade, assim, "a identidade passa a ser qualificada como pessoal (atributos específicos do indivíduo) e/ou identidade social (atributos que assinalam a pertenca a grupos ou categorias) " (JACQUES, 1998, p.161). Dito em outras 
palavras, Bernd (1988, p.309), fala que e o "eu sempre corresponde a nós (povo)." Nesse sentido, vale ressaltar que quando a palavra "negro", está escrita em letra minúscula, é como se ela representasse a memória da coletividade afro-brasileira.

Na sequência, ao repetir no primeiro verso o título do poema, o eu lírico reafirma $\mathrm{o}$ pertencimento a esse grupo. E equivale a compreensão de si como integrante a esssa comunidade, também promove um sentimento que particulariza e faz referência aos conceitos de identidade, na qual gera "o sentimento pessoal e a consciência da posse de um eu[...]" (BRANDÃO, 1990 p.37). Ainda, alimenta a noção de pertencimento a uma realidade peculiar a um grupo e a toma como referência, perante os outros.

Assim, o eu poético busca em seus versos capturar um ethos de signos de uma coletividade afrodescendentes. Embora esses signos já sejam utilizados na literatura canônica pelo branco. Mas no poema "Sou Negro" o sujeito lírico toma para si, a voz do discurso em primeira pessoa, reafirma sua identidade e protesta sobre toda invisibilidade apresentada a palavra "Negro". Assim, ressignifica o sentido quando assume ser "Negro". Essa palavra reaparece em quase todo o corpo do poema, sendo utilizado como símbolo principal, além de outros sentidos atribuídos a ela, de raça, cor, sujeira, preconceito, a partir de inúmeras relações de pertencimento estabelecidas com o contexto no qual o enunciador está inserido.

Nesse sentido, Hall (2006), fala que a questão de pertencimento, surge das nossas identidades culturais. Assim, do ponto de vista semântico, a palavra negro possui uma imagem significativa para o eu lírico, e ao dizê-la, legitima a cor da sua pele. Nesse sentido, Zilá Bernd (2011), afirma que na produção literária, a palavra negro/negra pode levar a identificação da cor da pele do autor. Essa autora também indaga que os termos afro-brasileira e negro são tidos como sinônimos, no entanto literatura afrobrasileira seria mais adequada, por remeter à origem étnica dos escritores e à comunhão de valores associados à cultura africana, "deixando de significar/remeter à existência de uma essência negra” (BERND, 2011, p. 20).

Contudo, partindo do princípio de que nomear significa muito mais do que atribuir um nome, percebe no poema que ao se denominar como negro e não afrodescendente, isto quer dizer que o eu lírico produz sentido de autoafirmação no interior do enunciado quando faz referência a cor de pele negra, pois atribui sentidos especiais ao grupo pertecente a essa cor, além de recortar da memória toda hostilização posta pela sociedade de dizeres acerca da pejorização posta a palavra negro e de ser negro, numa tentantiva de construir uma nova imagem de si no discurso, como tentativa de excluir a hierarquias de raças. Com isso, a opção pelo termo negro e não por afrodescendente, dá-se como a postura do sujeito lirista sobre o funcionamento língua no título do poema, na qual determina os espaços de enunciação, que são constituídos ao longo do poema por uma incessante autoafirmação de identidade negra. Assim, os discursos sobre as ações de exaltação da raça são afirmativas que mobilizam dizeres sustentados pelo eu lírico que ocupa determinadas posições sociais. Logo, compreendemos que ao optar por negro corrobora com suas posições acerca das questões raciais que perpassada pela ideologia do lugar social ocupado e almejado pelo sujeito lírico.

Assim, na segunda linha do poema é descrito "Negro sou sem mas ou reticências", observa-se que a palavra "Negro" está com letra maiúscula, o sujeito lirista personifica essa palavra, mais uma 
vez, o eu enunciador se assume negro, constrói uma imagem de si, um ethos, quando se manifesta porta-voz do enunciado. Numa tentava de romper com os discursos da ideologia hegemônica e, ao mesmo tempo, condói as dores marcada pela classe dominante e assume uma postura de combate, também demostrada pelo operador adversativo “mas" no segundo verso, que procura desvincular a negatividade do discurso anterior. Outro ponto a ser apresentando também nesse verso, são as reticências que vai além do silêncio, numa tentativa de romper as relações do discurso do outro que prologam os dilemas da sua raça.

Vale ressaltar, a intencionalidade do enunciador no discurso, pois através de dois versos, esteticamente invertidos, "Sou negro”, “Negro sou”, julga que no primeiro momento, os dois elementos textuais evidenciam a ação do lirista de pertencimento ao discurso, quando profere a palavra "sou” no início do verso. Enquanto, no segundo momento, coloca em evidência o sujeito “negro”. Dessa maneira, ao destacar no verso esse elemento, produz um indício de pertencimento étnico mais do que ação proferida de "ser". Neste ponto, a raça sobressai no interior da identificação do sujeito enunciador.

No verso que diz "Negro e pronto!", sua existência prevalece acima de qualquer outro discurso proferido pelo branco, mesmo em situação de discriminação, é quando emerge um sujeito étnico, mostrado no verso "Negro e pronto contra o preconceito branco”. Sobre esse sentimento de sofrimento social, o qual ocasiona um sentimento de pertencimento, Discini (2008) declara que,

[...] a enunciação finca o enunciado no lugar onde veio, ou seja, na sociedade e na História, o ator da enunciação, que é o enunciador [...], terá a imagem entendida em relação a um determinado sistema de restrições semânticas, social e histórico. (Discini, 2008, p.35)
Dessa maneira, quando o eu-lírico faz referências ao fenótipo biológico quando diz "Beiço/Pixaim/Abas largas meu nariz". Essas palavras fazem menção as características biológicas diferenciais desse grupo, ou seja, a imagem do enunciador é caracterizada como negra. Visto que “(...) o ethos se mostra no ato de enunciação, mas não se diz no enunciado.” (MAIGUENEAU, 2009, p.268). Isso quer dizer que esses elementos referenciais permitem ao leitor uma associação com esse grupo étnico, . Pois, "entende-se a noção de ethos como fundamento da noção de estilo (DISCINI, 2008, p.34). O estilo da literatura negra vem em oposição a produção literária brasileira do modelo estético do branco que predomina, ainda nos dias de hoje, pois esse nega a subjetividade negra, assim, apresentando pelo lirista no verso "Belo novo contra o velho belo imposto”.

Sobre essa questão, pode-se depreender o ethos de resistência a essa negação da estética dominante literária. Esse posicionamento contra o "velho imposto", supõe que é o discurso do "branco", na qual leva a ser compreendida como estratégia discursiva do enunciador "negro se revolta contra a ordem colonista onde ele é "aqueleque-é-olhado”e o branco “aquele-que-olha” (BERND, 2011, p. 29 ). Pode-se dizer, a intenção do sujeito lírico é incorporar um ethos em defesa de si mesmo e do seu povo. Nesse sentido, os elementos discursivos como "Sou negro/Pixaim/Abas largas meu nariz”, permitem ao leitor uma alusão de sentido com o grupo afrodescendente, manifestado entre um verso do enunciado e outro, expondo, assim, o estilo do eu-lírico. $\mathrm{E}$ ao compreender esses elementos o leitor constrói um corpo, compreendido semânticamente como encarnação do saber do sujeito sobre o mundo.

Em consonância com o pressuposto, Discini (2008) quando fala em estilo, pensa 
em um efeito de identidade produzido no texto, na qual caracteriza a imagem do enunciador, transmitida por marcas que individualizam a maneira de dizer. No verso “Batuca em mim”, o modo de dizer, julga-se como voz enunciativa, o qual suscita uma maneira de pensar, um ponto de vista, ou seja, o texto permite que o leitor compreenda a maneira que enunciador sente e interpreta as questões do mundo, na qual consente que o co-enunciador incorpore o ethos que se forma no discurso. A partir dessa descrição, o sujeito ao se identificar no discurso passa a co-enunciador, cria objetos simbólicos universais que permitem o reconhecimento da voz que surge em sua própria voz, que se predispõe a falar a verdade, nas quais ele possui ideias e as compartilha. Essa voz não diz a respeito ao som produzido pela fala, mas sim a maneira de pensar do enunciador sobre o mundo. Outro sentido atribuído ao verso “batuca em mim”, é a possibilidade de uma relação com a musicalidade na ato da leitura, na qual soa ao ritmo de batuque de capoeira, além de expressar um conjunto de símbolos de um determinado grupo, na qual permite ao leitor uma associação a comunidade étnico-racial. Nesse sentido, Mattos retrata que

\footnotetext{
A capoeira pode ser vista, da mesma forma que as irmandades religiosas e as reuniões em batuques, como um espaço construído por escravos e libertos, africanos e crioulos, para encontros e afirmação de apoio e de solidariedade entre os membros de um mesmo grupo. (MATTOS. 2008, p.185)
}

De certa forma, o ethos determina a construção de um corpo para o enunciador, e também promove um tom no espaço discursivo. Nesse aspecto, no texto escrito, esse tom promove ao leitor uma representação imaginária do corpo do enunciador, uma ação de incorporação. Esse corpo não é de uma pessoa real, mas subjetiva, denominada de figura do fiador que revela a representação corporal do enunciador na sentença. Maingueneau (2005a), declara que o fiador é uma imagem formada pelo co-enunciador, baseada nas marcas textuais. Um ethos determina pelo fiador por meio do discurso social no qual o leitor está inserido, para validar ou não o ethos da obra.

Quando o eu poético menciona no verso "Belo novo contra o velho belo imposto", ao assumir a voz do discurso para si, embarca numa tentantiva de mudança do discurso proferida pela sociedade dominante. Trabalha para desconstruir o modelo estético do branco, ao mencioná-lo no discurso, da seguinte maneira "Contra tudo que costuma me pintar de sujo/Ou que tenta me pintar de branco”, e tenta elaborar um estilo próprio "Belo e novo (...)". Esses sentidos pregados sobre a resistência, constituem um ethos identitário. Em conformidade com Bernd (2011), Cuti, expressa "uma linguagem corrosiva que se nutre, com frequência, do léxico de luta e de agressão contra uma realidade que se perpetua cem anos após a Abolição" (BERND, 2011, p. 144). Ainda, oportuniza mencionar pela densidade de presença do sujeito no texto, constatada pelos dêiticos "meu, mim, me", o ethos do poema coincide com o sujeito do discurso da enunciação. Nesta orientação, a presença do eu-enunciador que se faz presente em sua totalidade no poema, por meio dos dêiticos em primeira pessoa são elementos que atribuídos a literatura afro-brasileira. Pois, Bernd (1988), afirma que essa identificação em primeira pessoa, remete a uma estratégia do sujeito no discurso poético, visto que se expõe em sua plenitude, ao desvelar sua negritude.

Diante disso, através da identificação dos dêiticos "meu, mim, me", além de iniciar o poema da seguinte maneira "Sou negro/ Sou negro" e finalizar com "Negro pronto/ Negro e pronto”, essa afirmativa utilizada pelo eulírico para sustentar a estrátegia discursiva de um ethos referencial, na qual “determinada 
por um certo modo negro de ver e de sentir o mundo (...) pelo empenho de resgatar uma memória negra (BERND, 1988, p. 23), são elementos que permitem a construção de sentido, além de definir uma maneira de dizer, formando um estilo de um enunciatário que cria a imagem do enunciador que quer ser negro na poesia "Sou negro" de Cuti.

\section{CONSIDERAÇÕES FINAIS}

Como se pode ver, o ethos do eu-lírico na poesia negra, representa um modo de dizer que representa a imagem do sujeito negro, por meio de voz enunciativa no discurso poético de um eu-enunciador-que-se-quernegro. Essa voz encontra nas diversidades de expressões poéticas narrada pela pessoa que fala no poema em primeira pessoa, numa tentativa de emergir os discursos que foram silenciados pelo outro, um ethos que se pronúncia no enunciado, como sujeito negro, e mostra a sua maneira de sentir e de interpretar o mundo, pautando em signos significativos que dão indícios de pertencimento a esse grupo social.

Esse sentimento de identificação do sujeito lírista manifestada no texto, torna-se um ser que participa ativamente no discurso e forma um caráter do enunciador formando um corpo enunciativo, com marcas que apresentam uma voz peculiar de consciencia da cor negra, produzindo uma maneira de dizer dos povos negros, ou seja, um estilo próprio que caracteriza a literatura negra. Com isso, os discursos produzidos nos textos da literatura negra formam um corpo enunciativo que representam o ethos reivindicam e protestam contra os sistemas hegemônicos e majoritários, na buscam de vozes audíveis pautado no discurso consciente de reafirmacão e identitária. Dessa forma, nota-se que o ethos do sujeito negro no poema, ressignifica a palavra “negro” e entoa um canto de exaltação, com intuito de dá visibilidade a seu grupo étnico.
No que tange essa questão, este trabalho, permeiou a compreensão dos conceitos do ethos que possibilitou a constução da imagem do negro na poesia de Cuti, identificamos que o ethos do constrói a imagem de seu grupo étnico, tendo como referência o eu lírico que se manifesta na enunciação como eu enunciador que se quer ser negro, e torna-se pertencente a raça da cor negra. A partir de um dizer que se nomeia como sujeito negro, sendo possível visualizar a figura de um indivíduo afrodescendente no discurso poético que representa seu povo. Isso que dizer que é um um ethos identitário, pois por meio de sua representação como pessoa negra reafirmar a identidade de sua raça, partindo do ser individual para atingir o coletivo.

\section{REFERÊNCIAS}

AMOSSY, Ruth (org.). Imagens de si no discurso - a construção do ethos. Editora Contexto: São Paulo, 2008.

BRANDÃO, R. C. Identidade e etnia: construção da pessoa e resistência cultural. São Paulo: Brasiliense, 1990.

BERND, Zilá. Antologia de poesia afrobrasileira: 150 anos de consciência negra no Brasil. Belo Horizonte: Mazza Edições, 2011. . Introdução à literatura negra. São Paulo: Brasiliense, 1988.

BOSI, Alfredo. Literatura e Resistência. São Paulo: Companhia das Letras, 2002.

CERVO, Amado Luis; BERVIAN, Pedro Alcino. Metodologia científica: para uso dos estudantes universitários. 3. ed. São Paulo: McGraw-Hill do Brasil, 1983.

CUTI. Disponível em:

$<$ https://www.cuti.com.br/autordadosbiograficos $>$ Acesso em: 02 dez. 2018.

DENIS, Benoît. Literatura e engajamento: de Pascal a Sartre. São Paulo: EDUSC, 2002.

DISCINI, Norma. A propósito do ethos. In: MOTTA, Ana Raquel; Salgado, Luciana. Ethos discursivo. São Paulo: Contexto, 2008. 
Ethos e estilo. In: MOTTA, Ana Raquel;

Salgado, Luciana. Ethos discursivo. São Paulo:

Contexto, 2008.

FREYRE, Gilberto. “Aspectos da Influência

Africana no Brasil”. in ARAUJO Manuel (org)

Textos de negros e sobre Negros, São Paulo, Impressa Oficial do Estado de São Paulo, Museu Afrobrasil, 2011.

HALL, Stuart. Raça, o significante flutuante. Z Cultural, Revista do Programa Avançado de Cultura Contemporânea, ano VIII, n. 2, 2015.

A identidade cultural na pós-

modernidade. $7^{\text {a }}$ ed. Rio de Janeiro: DP\&A, 2006.

JACQUES, M. G. C. Identidade. In: M. N. Strey etal. Psicologia social

contemporânea. Petrópolis: Vozes, 1998.

MAINGUENEAU, Dominique. Discurso

Literário. São Paulo: Contexto, 2009.

. Análise de textos de comunicação. $4^{\mathrm{a}}$.

ed., São Paulo: Cortez Editora, 2005a.

2005b.

. A gênese dos discursos. Curitiba: Criar,

. Novas tendências em análise do

discurso. Campinas: Martins Fontes, 1997.

MATTOS, Regiane A. História e cultura afro-

brasileira. Contexto: São Paulo, 2008.

PROENÇA FILHO, Dominício. A Trajetória do

Negro na Literatura Brasileira. In: Estudos

avançados 50, dossiê O negro no Brasil. São

Paulo: Instituto de Estudos Avançados, 2004.

SEVERINO, Antônio Joaquim. Metodologia do

trabalho científico. 23. ed. rev. E atual. São

Paulo: Cortez, 2007. 